\title{
Colorectal cancer prevention
}

\author{
Montse Andreu • Mercè Marzo • Juanjo Mascort • Enrique Quintero • Pilar García-Alfonso • Cristina López-Ibor • \\ Toni Castells $\cdot$ Pedro Pérez Segura on behalf of Alliance for the Prevention of Colon Cancer in Spain
}

$\mathrm{C}$ olorectal cancer (CRC) is a major health problem in Western countries. In Spain it represents approximately $15 \%$ of all tumours, with over 25,000 new cases recorded each year. It is the second leading cause of death due to cancer, causing over 13,000 deaths per year. In Spain the mean survival rate for CRC five years after diagnosis is $48 \%$. This may be due to the fact that in most cases it is diagnosed late and few prevention programmes have been established for this type of neoplasia [1-3].

There is widespread consensus with regard to the need to raise awareness of the importance of CRC prevention among the population, healthcare professionals and the health authorities. It is a common field of interest for primary care professionals, specialists (gastroenterology, surgery, medical oncology, and medical and gene radiotherapy, among others) and public health professionals. Primary prevention measures (healthy lifestyles) and screening of medium-risk groups must be encouraged in all areas of healthcare.

CRC fulfils the necessary conditions for screening, as its natural history is known, screening tests and diagnostic methods with proven efficacy are available that are applicable to the healthy population without involving excessive risks, and treating it at an early stage improves the disease's prognosis. Moreover, it is a cost-effective intervention. European Union Council directives, the Comprehensive Cancer Plan and various regional Health Plans recommend the application of population screening for CRC with faecal occult blood tests (FOBT) in men and women aged 50-74 [4].

\footnotetext{
NB This editorial is published at the same time as the March 2009 issue of the following societies' journals: Spanish Association of Gastroenterology; Journal of the Spanish Society of Epidemiology (SEE); Spanish Society of Family and Community Medicine (semFYC); Spanish Society of Medical Oncology (SEOM); Clinical and Translational Oncology, published by the Federation of Spanish Oncology Societies (FESEO); Spanish Society of Radiation Oncology (SEOR); Spanish Association against Cancer (AECC) and EuropaColon-Spain.
}

In order to raise awareness of the importance of CRC and to promote preventative measures, five scientific societies (Spanish Association of Gastroenterology [AEG Asociación Española de Gastroenterología], Spanish Society of Epidemiology [SEE - Sociedad Española de Epidemiología], Spanish Society of Family and Community Medicine [semFYC - Sociedad Española de Medicina Familiar y Comunitaria], Spanish Society for Medical Oncology [SEOM - Sociedad Española de Oncología Médica] and Spanish Society of Radiation Oncology [SEOR - Sociedad Española de Oncologia Radioterápica]) and two non-governmental organisations (Spanish Association against Cancer [AECC - Asociación Española contra el Cáncer] and EuropaColon-Spain) have decided to join forces and establish the Alliance for the Prevention of Colon Cancer in Spain (Alianza para la Prevención del Cáncer de Colon en España). This alliance, which is backed by the Ministry of Health and Consumer Affairs, has been specifically created to promote different scientific, social and media events and activities all over Spain throughout 2009, particularly in March, which is the European month of colon cancer. These activities, which are being organised at a nationwide and regional level, are aimed at both medical and healthcare management professionals and the general public. Among other activities, they include: an advertising campaign in the general and specialised media, scientific and/or informative meetings at medical, pharmaceutical and nursing colleges, universities, hospitals, health centres, residents' associations and other public and private organisations that are involved in prevention, and training events for different specialists (primary healthcare, gastroenterology, oncology, surgery, public health, epidemiology, occupational health, etc.). The high point of this campaign will be the "Spanish Day of Colon Cancer Prevention" on 31 March.

On the Spanish Day of Colorectal Cancer Prevention, a second version of the Clinical Practice Guidelines for Colorectal Cancer Prevention [5] will be published under the programme "Preparation of Clinical Practice Guidelines in Digestive Diseases, from Primary to Specialist Healthcare". In this new version, the available scientific evidence has been updated, as have the recommendations regarding primary prevention, populations at risk of developing CRC, 
screening for CRC in medium-risk groups, screening for familial adenomatous polyposis, screening for hereditary nonpolyposis cancer, screening for familial CRC, monitoring of colorectal adenomas and monitoring in inflammatory bowel disease.

At present, only three autonomous regions (Catalonia, Murcia and Valencia) have a CRC screening programme, although most autonomous regions are planning to establish one. Participation in these programmes and the follow-up rates are low, below the rates for other cancer prevention programmes. This low participation is partly due to the fact that the importance of CRC prevention and screening programmes is unknown, both by the general population and by some healthcare professionals, and the examinations that are performed are believed to be painful and unpleasant.

Certain prestigious scientific societies and clinical practice guidelines recommend screening for everyone over the age of 50 without additional risk factors and for high-risk groups [6-9]. Although there is no single strategy for population screening (biochemical or immunological FOB tests every 1 to 2 years, sigmoidoscopy every 5 years, colonoscopy every 10 years), most programmes use the FOB test. However, it is necessary to conduct studies that enable us to identify the best method and the best application strategy. To do this, the Spanish Association of Gastroenterology has initiated a randomised, multicentre clinical trial in a medium-risk population, which will be carried out in 9 autonomous regions in Spain (Aragon, the Canary Islands, Catalonia, Extremadura, the Basque Country, Galicia, Madrid, Murcia and Valencia) to assess the efficacy of colonoscopy compared with the immunological FOB test. This ambitious project has already begun in Murcia and has benefited from grants from the Spanish Association against Cancer and the Carlos III Health Institute.

The achievements and knowledge gained in reducing mortality due to breast cancer provide useful experience for implementing CRC screening in the coming years. Primary and specialist healthcare professionals must be a clear source of reference for the population. It is essential that the different autonomous regions use coordination and teamwork to design and organise these programmes. The DESCRIC report, issued by the Quality Agency of the Ministry of Health and Consumer Affairs on the situation of early diagnosis of cancer in Spain, states that an information system is needed to help manage the target population and monitor the process and the assessment of the results, and it also states that, as far as possible, organised programmes with active multidisciplinary participation should be favoured, guaranteeing and improving the information on the benefits and risks of participating in a programme for the early detection of cancer. Coordination with other European countries will also help to achieve the objectives of a high-quality CRC screening programme [10].

The scientific societies and institutions that have established the Alliance for the Prevention of Colon Cancer in Spain consider that most cases of CRC could be prevented and that there should be a high degree of consensus with regard to the need to establish CRC screening programmes for medium-risk groups. It is important to raise awareness among the population of the benefits of prevention and early diagnosis and to facilitate access to healthcare resources. Initiatives such as the cancer prevention day will help to raise everyone's awareness of the importance of this disease, which can certainly be prevented.

\section{References}

1. Planificación Sanitaria (2005) La situación del Cáncer en España. Ministry of Health and Consumer Affairs, Madrid

2. (2003) Informe sobre la salud de los españoles Cáncer. National Centre of Epidemiology (Centro Nacional de Epidemiología). December

3. López-Abente G, Pollán M, Aragonés N et al. (2004) Situación del cáncer en España: incidencia. An Sis San Navarra 27:165-173

4. (2004) Improving outcomes in colorectal cancers. National Institute for Clinical Excellence. May

5. Grupo de trabajo de la Guía de práctica clínica de prevención del cáncer colorrectal [Work group for the Clinical practice guidelines for the prevention of colorectal cancer] (2004) Guía de práctica clínica [Clinical practice guidelines]. Spanish Association of Gastroenterology, Spanish Society of Family and Community Medicine and Latin Ame- rican Cochrane Centre, Barcelona. Programa de Elaboración de Guías de Práctica Clínica en Enfermedades Digestivas, desde la Atención Primaria a la Especializada [Programme for the Preparation of Clinical Practice Guidelines on Digestive Diseases, from Primary to Specialist Healthcare), p 4

6. Levin B, Lieberman DA, McFarland B et al; American Cancer Society Colorectal Cancer Advisory Group; US Multi-Society Task Force; American College of Radiology Colon Cancer Committee (2008) Screening and surveillance for the early detection of colorectal cancer and adenomatous polyps: a joint guideline from the American Cancer Society, the US Multi-Society Task Force on Colorectal Cancer, and the American College of Radiology. Gastroenterology 134: 1570-1595

7. Leddin D, Hunt R, Champion M et al; Canadian Association of Gastroenterology; Canadian Digestive Health Foundation (2004) Canadian Asso- ciation of Gastroenterology and the Canadian Digestive Health Foundation: guidelines on colon cancer screening. Can J Gastroenterol 18:93-99

8. Keighley MR (2003) Gastrointestinal cancers in Europe. Aliment Pharmacol Ther 18[Suppl 3]:730

9. Whitlock EP, Lin JS, Liles E et al (2008) Screening for colorectal cancer: a targeted, updated systematic review for the U.S. Preventive Services Task Force. Ann Intern Med 149:638-658

10. Castells X, Sala M, Ascunce N et al coordinadores (2007) Descripción del cribado del cáncer en España [Description of cancer screening in Spain]. DESCRIC project. Madrid Plan de Calidad para el Sistema Nacional de Salud [Madrid Quality Plan for the National Health System]. Ministry of Health and Consumer Affairs. Agència d'Avaluació de Tecnologia i Recerca Mèdiques de Cataluña. Informes de Evaluación de Tecnologías Sanitarias [Health Technology Evaluation Reports], AATRM no.2006/01 